International Research Journal of Public Health
(ISSN:2573-380X)

\title{
Overview on Physical Violence Against Women Between 2009 and 2018 in Brazil
}

\section{Vítor Pereira Contini*; Gabriela Vasconcelos de Moura; Laura de Lima Bigolin; Julia Perito Alfredo}

Universidade Católica de Pelotas

\section{ABSTRACT}

Objectives: To determine the existence of a pattern of women most frequently victims of physical violence in Brazil over a period of 10 years. Methods: Data from the DATASUS platform were collected on the records of domestic, sexual and other violence, registered by physical violence against female persons between 2009 and 2018. Data from the Violence and Accident Surveillance System on characteristics of the violent act against women were also collected. The Brazilian Institute of Geography and Statistics was also used to collect data from the National Household Sample Survey (PNAD). For bibliographic reference, the descriptors "Domestic and Sexual Violence against Women", "Domestic Violence" and "Domestic Violence" were searched on virtual data basis and Brazilian articles that were published within the period of the present study were included. Results: There is a continuous and rapid increase in the first half of the study period, with a slight deceleration between 2014 and 2016, followed by a new jump in records from 2017. As for race, the largest numbers are white women, 348428, and browns, 308902. Black women represent $68.25 \%$ of the total records of domestic, sexual and other violence, with $8.3 \%$ of the total records of physical violence. Conclusion: It is possible to estimate that black women are not making complaints or possibly are not being seen with due care to make them. As it is data that depends on denunciation, which is often not carried out, the results need consideration regarding assertiveness and reflection of reality.

Keywords: domestic violence, physical violence, physical aggression.

*Correspondence to Author:

Vítor Pereira Contini

Universidade Católica de Pelotas

How to cite this article:

Vítor Pereira Contini; Gabriela Vasconcelos de Moura; Laura de Lima Bigolin; Julia Perito Alfredo.Overview on Physical Violence Against Women Between 2009 and 2018 in Brazil.International Research Journal of Public Health, 2021; 5:52.

\section{eScî̀Pub}

eSciPub LLC, Houston, TX USA. Website: https://escipub.com/ 


\section{INTRODUCTION}

Historically women have been repressed and diminished by machismo, in violent or nonviolent ways, from occupying inferior positions to homicide. The National Continuous Household Sample Survey (PNAD) of 2018 pointed out that women receive, on average, $79.5 \%$ of what men receive, with women between 25 and 49 years old receiving about $R \$ 500$ less than men in the same range age.

Still in the employment and remuneration scenario, women represent $45.3 \%$ of the employed people in the country. This value has remained constant, with small changes, since 2012. On the other hand, when the population's level of education is analyzed, there is a significant evolution in the period. While $13.1 \%$ of men with higher education now account for $18.4 \%$, women have gone from $16.5 \%$ to $22.8 \%$.

Violence can be subdivided into several forms, for example, physical, psychological, sexual etc. and women, children and the elderly are considered vulnerable, more susceptible. Physical violence is understood as a violent act in which physical force is intentionally used in order to injure and cause pain and suffering.

According to the Violence and Accident Surveillance System (VIVA) ${ }^{[4]}$ and the Notifiable Diseases Information System (SINAN) in 2014, only $8.5 \%$ of records of violence against women were caused by unknown persons. Partners and ex-partners were responsible for $46 \%$ of these records in the same year. Such information reinforces the idea of structural machismo and that the danger, to the physical integrity of the woman, most of the time is among the known people, who should be synonymous with welcoming and security.

The present study aims to study the frequency of records of physical violence in Brazil over a 10-year period, from 2009 to 2018, and, based on information about these victims, to establish a possible pattern that has been most affected.

\section{METHODS}

Were collected, from August to October 2020, through the Disease Information and Notification System - SINAN, made available by the Informatics Department of the Unified Health System (DATASUS), as well as data from the Violence and Accident Surveillance System (VIVA) , data referring to domestic, sexual and other violence, recorded by physical violence, to female persons, between the years 2009 and 2018. The data were studied together and separately, regarding the level of education, race and age group of the victims. Information was also collected from the Brazilian Institute of Geography and Statistics (IBGE), using data from the 2018 National Household Sample Survey (PNAD) ${ }^{[5]}$.

For the purpose of bibliographic comparison, articles on physical violence against women were searched in the PubMed and Google Scholar virtual databases between August and October 2020. 3 original studies were included. The indexed descriptors were searched in DECs in Portuguese, being: "Domestic and Sexual Violence against Women", "Domestic Violence" and "Domestic Violence". As a criterion for inclusion and exclusion, the year of publication was considered, excluding those who were outside the period of the present study. In addition, studies that assessed domestic violence in other Portuguese or Englishspeaking countries were also disregarded.

\section{RESULTS}

Of a total of 1343932 notifications of domestic, sexual and other violence (VDS) recorded in the period studied, a total of 866110 were related to physical violence (VF), representing $64.45 \%$. The data presented are from 2009 to 2018, with an increase from 16009 in the first year to 150055 in the last. The highest frequency of notifications of physical violence occurred in 2014 with 67.86\%, with another approximate peak in 2011, representing $67.63 \%$, as shown in Table 1. Despite the increasing number, the rate of physical violence remains with similar proportions, oscillating between $59.38 \%(2018)$ and $67.86 \%$ (2014). 
Table 1 - Data on Physical Violence against Women between 2009 and 2018

\begin{tabular}{|l|l|l|}
\hline Year & Absolute number of VF & \% referring to total VDS \\
\hline 2009 & 16009 & $60.26 \%$ \\
\hline 2010 & 30680 & $62.52 \%$ \\
\hline 2011 & 50745 & $67.63 \%$ \\
\hline 2012 & 72174 & $66.20 \%$ \\
\hline 2013 & 86868 & $65.72 \%$ \\
\hline 2014 & 97691 & $67.86 \%$ \\
\hline 2015 & 105446 & $66.32 \%$ \\
\hline 2016 & 115301 & $65.54 \%$ \\
\hline 2017 & 141141 & $63.99 \%$ \\
\hline 2018 & 150055 & $59.38 \%$ \\
\hline
\end{tabular}

The notifications increase with large steps and the studied period, with a slight deceleration can be better seen in Graph 1. There is a between 2014 and 2016, followed by another continuous and rapid increase in the first half of jump in records from 2017.

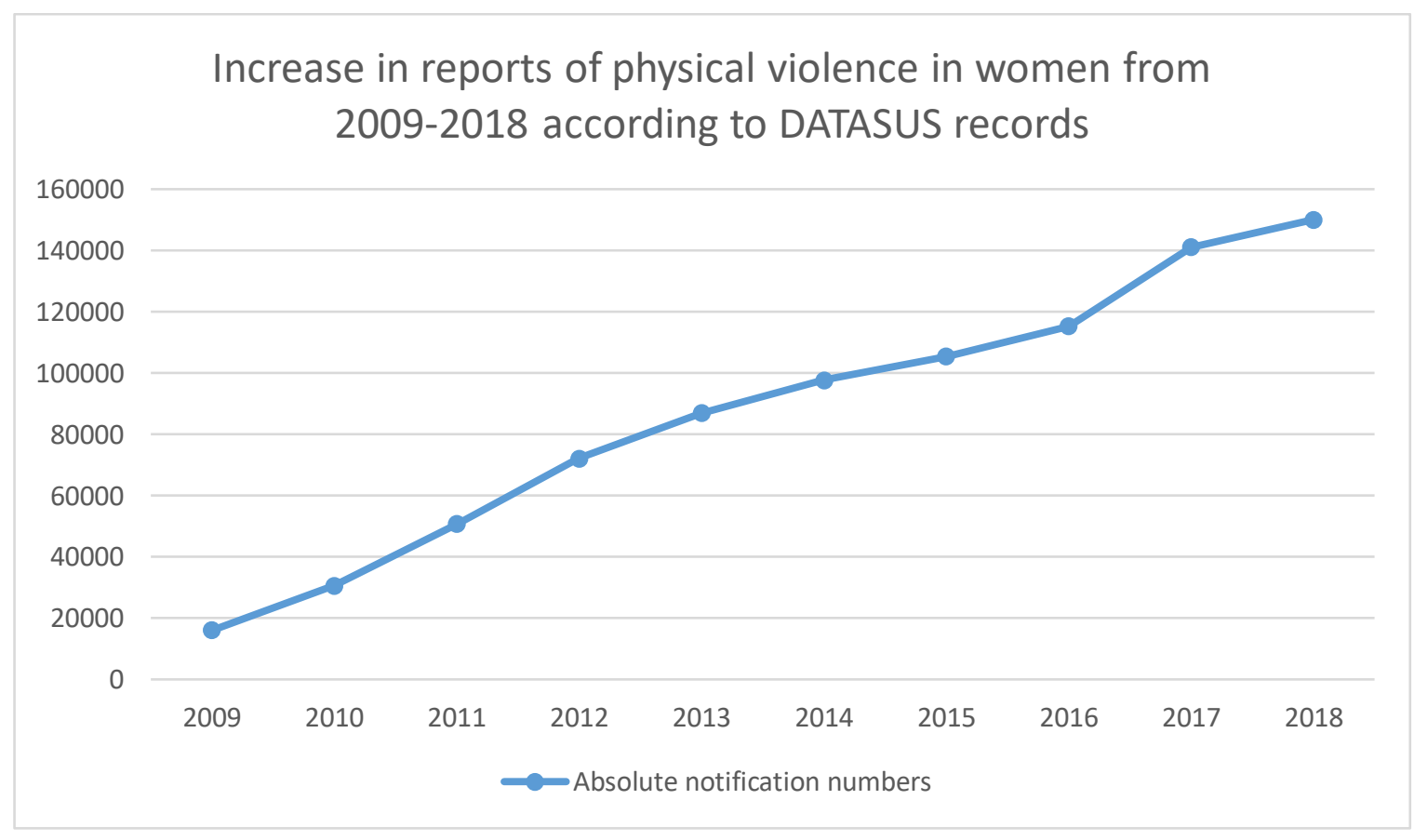

As for race, also separated by the female sex, that race. Brown women are responsible for $35 \%$ the largest numbers are white women, 348428, of the VF records, which corresponds to $64.59 \%$ and brown, 308902. White women alone of the total VDS registered by this race, as represent $40 \%$ of the total cases of physical violence, which corresponds to $62.18 \%$ of total domestic, sexual and other violence recorded by shown in Table 2.

Black women represent $68.25 \%$ of the total records of domestic, sexual and other violence, 
with $8.3 \%$ of the total records of physical violence. Among indigenous women, 70.34\% (6816) of the total records count as physical violence. Regarding the total of physical violence without racial distinction, the group in question corresponds to $0.78 \%$ of the notifications. Accordingly, yellow women represent $0.71 \%$ of the records of physical violence. Among them, this type of violence corresponds to $64.59 \%(6,187)$ of the total domestic, sexual and other violence.

Regarding the age group, the highest absolute number is between 20 and 29 years old, with 247070 notifications representing $28 \%$ of the total of physical violence. Consequently, it is also the age group with the highest notification of VDS, with VF representing $78 \%$ of records.
Then, between 30 and 39 years old, the records correspond to 23\% (203091) of the total VF. Records of physical violence among women under 19 years of age to children under 1 year old represent $25.09 \%$ (217353) of the total VF records.

As for the level of education, the highest numbers are concentrated among women who concluded that they completed only elementary school (1st to 8th grade), the second part of which (5th to 8th grade incomplete) representing the highest number of notifications of VF, with 122774 (14\%). Women with complete high school are in second place with 115927 (13.34\%). Only $1.1 \%$ (10357) of the total records of physical violence were carried out by illiterate women.

\begin{tabular}{|l|l|l|}
\hline Race & \% in relation to VDS & $\begin{array}{l}\% \text { notifications regarding total } \\
\text { physical violence }\end{array}$ \\
\hline White & $62.18 \%$ & $40 \%$ \\
\hline Black & $68.25 \%$ & $8.3 \%$ \\
\hline Yellow & $68.22 \%$ & $0.7 \%$ \\
\hline Brown & $64.69 \%$ & $35 \%$ \\
\hline Indigenous & $70.34 \%$ & $0.78 \%$ \\
\hline
\end{tabular}

\section{DISCUSSION}

In relation to 2010 , the number of notifications, when compared to the previous year, represented an increase rate of $91.5 \%$. This rate can only be observed again when comparing non-consecutive years, such as 2011 and 2014, with a very similar rate of increase, $92.5 \%$. In addition, records continue to grow exponentially until 2018, the last year that data is accessed, with a 9-fold increase over the initial year. This increase can be justified by some factors, such as, for example, greater access to support networks and female empowerment, as well as greater dissemination of information and implementation of the disk denunciation through the number 180, which operates 24 hours a day.
The data also shows us that, although the total number of VF notifications is increasing, the percentage of this type of violence has decreased, that is, other violence, such as sexual violence, has proportionally increased. The data also shows us that although the total number of notifications of physical violence is increasing, there is a tendency for this percentage to decrease, being that in the last year it represented the lowest

As for the racial distribution of physical violence, it was observed that white women are responsible for the highest number of notifications followed by brown women. Despite having the highest absolute number in relation to VF notifications, they are not the majority of the 
population. According to preliminary data from IBGE in the National Continuous Household Sample Survey of $2018^{[5]}$, they represent $43.1 \%$, in contrast, brown women are $46.5 \%$ according to the same statistics. (Perfect)

In the scenario of VF notifications, black women have the third highest number of records, despite having a frequency of notifications of this type 5 times lower when compared to the frequency of white women. Data from IBGE's study of social inequalities, which compares the homicide rate for every 100,000 young people aged 15 to 29, shows that black women have a homicide rate almost twice as high as white women $(5.1 \%$ of white women to $10.1 \%$ of black women), which explains the disparity between realities. This data is somewhat contradictory considering the Brazilian demography it represents $55.8 \%$ of the black and brown population, according to the same study. From the same demographic perspective, there is a need to think of data from yellow and indigenous women as a smaller portion of the population and, therefore, have a small relative representation in relation to the total number of records of violence.

From the perspective of the age group of these women, it is possible to see that the greatest number of occurrences occurs in the age group of 20 to 39 years. Thus, it is the scenario in which the woman has greater autonomy in relation to herself, sometimes with her own job and home, and therefore has greater support for reporting. Also, the age at which affective bonds are created that may be the genesis of the aggressions, LEITE (2019) ${ }^{[1]}$ proved that the prevalent profile of aggressors are men, without occupation and who abuse alcohol. Domestic violence caused by a spouse is one of the main focuses of campaigns today, which aim to empower women to break this bond that can cause physical, financial and mental damage.

It is also inferred that violence during childhood and adolescence corresponds to $25.05 \%$ (1/4) of the total, which points more clearly to domestic violence. In this sense, ANTUNES $(2020)^{3}$ showed that factors such as being black and brown, in addition to the use of alcohol and bullying, contribute significantly to domestic violence. In addition, preliminary data from IBGE in the National Continuous Household Sample Survey of 2018 in the percentage study of schoolchildren attending the 9th grade of elementary school who were physically assaulted by any adult in the family at any time during the 30 days, show that aggressions by black and brown (15.1\%) are higher than white $(13.1 \%)$ in the same segment.

As for the level of education, it is not possible to establish a proportional relationship when it comes to the highest level of education and the increase in the number of complaints. It is possible to verify that illiterate women have the lowest absolute number of records of violence, in contrast, women with complete higher education are not the highest notifications of VF and VDS. Also according to preliminary data from IBGE in the National Continuous Household Sample Survey of 2018, it attests that illiteracy is almost 3 times higher in black and brown people $(9.1 \%)$ compared with whites (3.9\%). The highest number of VF notifications is concentrated in two peaks: those with incomplete elementary and complete average. As these are women of school age and greater family contact, the network of support and assistance for complaints is facilitated. LEITE $(2019)^{3}$ showed that family members present who understand the problem is a strong protective factor in relation to intrafamily violence.

\section{CONCLUSION:}

Regarding the total number of records and analysis of each relative percentage, it is possible to estimate that black women are not making complaints or possibly are not being seen with due care to make them. As these are data that depend on denunciation, which is often not carried out, the results need to be considered regarding assertiveness and reflection of reality. In addition, there is a high prevalence of violence directed at children and adolescent women with 
aggravating variables and corroborates with a greater number of records in the mentioned school period (elementary school II and high school). Also the growing number of notifications of VDS but the relative percentage of VF decreased, attentive to women suffering other types of violence, such as psychological, sexual and financial.

\section{REFERENCES}

[1]. Leite Franciéle Marabotti Costa, Luis Mayara Alves, Amorim Maria Helena Costa, Maciel Ethel Leonor Noia, Giant Denise Petrucci. Violence against women and their association with the intimate partner profile: a study with primary care users. Rev. bras. epidemiol. [Internet]. 2019 [cited 2020 Oct 30]; 22: e190056. Available from: http://www.scielo.br/scielo.php?script=sci_arttext \&pid=S1415-790X2019000100455\&lng=en.

Epub Dec 05, 2019. https://doi.org/10.1590/1980549720190056.

[2]. Garcia Leila Posenato, Duarte Elisabeth Carmen, Freitas Lúcia Rolim Santana de, Silva Gabriela Drummond Marques da. Domestic and family violence against women: case studies and controls with victims treated in urgent and emergency services. Cad. Saúde Pública [Internet]. 2016 [cited 2020 Oct 30]; 32 (4): e00011415. Available from: http://www.scielo.br/scielo.php?script=sci_arttext \&pid $=S 0102-311 X 2016000400704 \&$ Ing $=$ en.

Epub Apr 19, 2016. https://doi.org/10.1590/0102311 X00011415.

[3]. Antunes Juliana Teixeira, Machado Ísis Eloah, Malta Deborah Carvalho. Risk and protection factors related to intrafamily violence against Brazilian adolescents. Rev. bras. epidemiol. [Internet]. 2020 [cited 2020 Oct 30]; 23 (Suppl 1): e200003.SUPL.1. Available from: http://www.scielo.br/scielo.php?script=sci_arttext \&pid=S1415-790X2020000200401\&lng=en. Epub July 03, 2020. https://doi.org/10.1590/1980549720200003.supl.1.

[4]. Ministry of Health. Viva: instruction on the notification of domestic, sexual and other violence [Internet]. 1st ed. Brasília: [publisher unknown]; 2011 [cited 2020 Oct 7]. Available from: https://crianca.mppr.mp.br/arquivos/File/sinan/viv a_instrutivo_not_viol_domestica_sexual_e_out.p $\mathrm{df}$

[5]. IBGE, compiler. National Household Sample Survey [bibliography on the Internet]. 1st ed. [place unknown: publisher unknown]; 2018 [cited 2020 Oct 8]. Available from: https://www.ibge.gov.br/estatisticas/multidominio/ genero/20163-estatisticas-de-generoindicadores-sociais-das-mulheres-nobrasil.html?=\&t=resultados

[6]. IBGE, compiler. Informação Demográfica e Socioeconômica: Desigualdades Sociais por Cor ou Raça no Brasil [bibliography on the Internet]. 41th ed. [Brasil; São Paulo]; 2019 [cited 2020 Oct 3]. Available from: https://biblioteca.ibge.gov.br/visualizacao/livros/li v101681_informativo.pdf 
- Title: International Research Journal of Public Health

- ISSN: 2573-380X

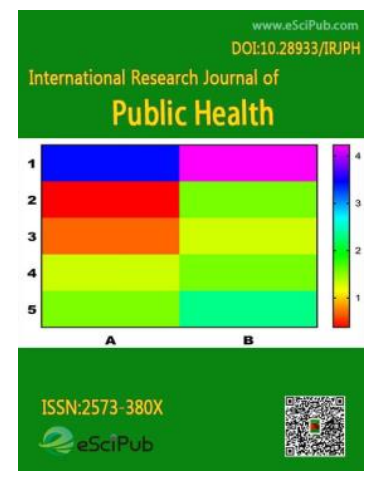

- DOI: $10.28933 / \mathrm{IRJPH}$

- IF: 1.36 (citefactor)

- Email: IRJPH@escipub.com

- TEL: +1-281-656-1158

\title{
About the journal
}

The journal is hosted by eSciPub LLC. Our aim is to provide a platform that encourages publication of the most recent research and reviews for authors from all countries.

\begin{abstract}
About the publisher
eSciPub LLC is a publisher to support Open Access initiative located in Houston, Texas, USA. It is a member of the largest community of professional publishers in the United States: the Independent Book Publishers Association. It hosts more than 100 Open Access journals in Medicine, Business \& Economics, Agriculture, Biological Sciences, Chemistry, Education, Physical Sciences, Sociology, and Engineering and Technology.
\end{abstract}

\section{Rapid Response Team}

Please feel free to contact our rapid response team if you have any questions. Our customer representative will answer your questions shortly.

\section{BY 4.0}

This work and its PDF file(s) are licensed under under a Creative Commons Attribution 4.0 International License.

\section{Terms of Use/Privacy Policy/ Disclaimer/ Other Policies:}

You agree that by using our site, you have read, understood, and agreed to be bound by all of our terms of use/privacy policy/ disclaimer/ other policies (click here for details). This site cannot and does not contain professional advice. The information on this site is provided for general informational and educational purposes only and is not a substitute for professional advice. Accordingly, before taking any actions based upon such information, we encourage you to consult with the appropriate professionals. We do not provide any kind of professional advice. The use or reliance of any information contained on this site or our mobile application is solely at your own risk. Under no circumstance shall we have any liability to you for any loss or damage of any kind incurred as a result of the use of the site or our mobile application or reliance on any information provided on the site and our mobile application. We may publish articles without peer-review. Published articles of authors are open access. Authors hold the copyright and retain publishing rights without restrictions. Authors are solely responsible for their articles published in our journals. Publication of any information in authors' articles does not constitute an endorsement by us. We make no representation or warranty of any kind, express or implied, regarding the accuracy, adequacy, validity, reliability, availability or completeness of any information that authors provided. more..... 